\title{
Single-item memory, associative memory, and the human hippocampus
}

\author{
Jeffrey J. Gold, ${ }^{3}$ Ramona O. Hopkins, ${ }^{5,6}$ and Larry R. Squire ${ }^{1,2,3,4,7}$ \\ ${ }^{1}$ Veterans Affairs Medical Center, San Diego, California 92161, USA; ${ }^{2}$ Department of Psychiatry, University of California, San \\ Diego, La Jolla, California 92093, USA; ${ }^{3}$ Department of Neurosciences, University of California, San Diego, La Jolla, California \\ 92093, USA; ${ }^{4}$ Department of Psychology, University of California, San Diego, La Jolla, California 92093, USA; ${ }^{5}$ Psychology \\ Department and Neuroscience Center, Brigham Young University, Provo, Utah 84602, USA; ${ }^{6}$ Department of Medicine, Pulmonary \\ and Critical Care Division, LDS Hospital, Salt Lake City, Utah 84143, USA
}

\begin{abstract}
We tested recognition memory for items and associations in memory-impaired patients with bilateral lesions thought to be limited to the hippocampal region. In Experiment 1 (Combined memory test), participants studied words and then took a memory test in which studied words, new words, studied word pairs, and recombined word pairs were presented in a mixed order. In Experiment 2 (Separated memory test), participants studied single words and then took a memory test involving studied word and new words. In a separate test, they studied word pairs and then took a memory test involving studied word pairs and recombined word pairs. In both experiments, patients were impaired at memory for single items as well as memory for associations, suggesting that the hippocampus is important for both of these memory functions. In Experiment 1, patients appeared to be more impaired at associative memory than item memory. In Experiment 2, patients were similarly impaired at associative memory and item memory. These different findings are considered, including the fact that in Experiment 1 the results depended on the fact that controls produced unexpectedly low false-alarm rates to recombined pairs. We discuss single-item and associative memory from the perspective that the hippocampus and adjacent cortex work cooperatively to signal recognition and that simple dichotomies do not adequately describe the division of labor within the medial temporal lobe.
\end{abstract}

Declarative memory depends on structures within the medial temporal lobe, including the hippocampal region (subicular complex, CA fields, and dentate gyrus) and the adjacent perirhinal, entorhinal, and parahippocampal cortices (Burwell et al. 1996; Lavenex and Amaral 2000; Squire et al. 2004). A wellstudied example of declarative memory is recognition memory, the ability to judge an item as having been encountered previously. A fundamental issue concerns whether specific regions of the medial temporal lobe contribute differently to recognition memory or whether recognition memory depends broadly on the medial temporal lobe.

It has been proposed that recognition memory judgments for items are supported by different neural substrates than recognition memory judgments for associations between items, for example that the hippocampus is especially important for associative memory and the adjacent cortex is more important for single-item memory (e.g., Eichenbaum et al. 1994; Henke et al. 1997, 1999; Brown and Aggleton 2001). Several studies have addressed this issue by administering single-item and associative recognition memory tasks to memory-impaired patients (e.g., Kroll et al. 1996; Stark et al. 2002; Giovanello et al. 2003; Stark and Squire 2003; Mayes et al. 2004; Turriziani et al. 2004). These studies involved patients with various amounts of damage to the hippocampal region, adjacent cortex, and other structures. The findings from these studies have been mixed.

In the present study, we administered tests of single-item memory and associative memory to memory-impaired patients with damage limited to the hippocampal region. The first experiment used the same procedure employed in a recent study of memory-impaired patients, which reported greater impairment

\section{${ }^{7}$ Corresponding author.}

E-mail Isquire@ucsd.edu; fax (858) 552-7457.

Article published online before print. Article and publication date are at http:// www.learnmem.org/cgi/doi/10.1101//m.258406. in associative memory than in single-item memory (Giovanello et al. 2003). The second experiment compared single-item memory and associative memory using a different procedure intended to provide more independent measures of single-item memory and associative memory.

\section{Results}

\section{Experiment 1: Combined memory test}

When each pair of words on the study list was viewed once, patients $(\mathrm{H})$ were impaired relative to controls $(\mathrm{CON})$ on both single-item memory $(15.3 \pm 6.0 \%$ vs. $63.5 \pm 7.6 \%, P<0.01)$ and associative memory $(7.0 \pm 2.6 \%$ vs. $69.8 \pm 3.6 \%, P<0.01)$ (Fig. $1)$. The patients scored above chance level on both measures $(P<0.05)$. When patients $(\mathrm{H} 6 \times)$ saw each pair of words six times, their scores matched the scores of controls for single-item memory $(70.1 \pm 6.8 \%$ vs. $63.5 \pm 7.6 \%, P>0.50)$ but were lower than the scores of controls for associative memory (45.1 $\pm 8.2 \%$ vs. $69.8 \pm 3.6 \%, P<0.01$ ) (Fig. 1). Repeated measures ANOVA revealed a group $\times$ test interaction $(P<0.01)$. Table 1 shows the hit rates and false-alarm rates for all three conditions $(\mathrm{CON}, \mathrm{H}$, and $\mathrm{H} 6 \times$ ).

An analysis of discriminability $\left(\mathrm{d}^{\prime}\right)$ yielded similar results. Patients $(\mathrm{H})$ were impaired relative to controls $(\mathrm{CON})$ on both single-item memory $(0.42 \pm 0.16$ vs. $2.00 \pm 0.26, P<0.01)$ and associative memory $(0.18 \pm 0.07$ vs. $2.23 \pm 0.17, P<0.01)$. When patients $(\mathrm{H} 6 \times)$ saw each pair of words on the study list six times, their scores matched the scores of controls for single-item memory $(2.27 \pm 0.33$ vs. $2.00 \pm 0.26, P>0.50)$ but not for associative memory $(1.36 \pm 0.30$ vs. $2.23 \pm 0.17, P<0.01)$. Repeated measures ANOVA revealed a group $\times$ test interaction $(P<0.01)$.

\section{Experiment 2: Separated memory test}

When each word (or pair of words) on the study list was viewed once, patients $(\mathrm{H})$ were impaired relative to controls $(\mathrm{CON})$ on 


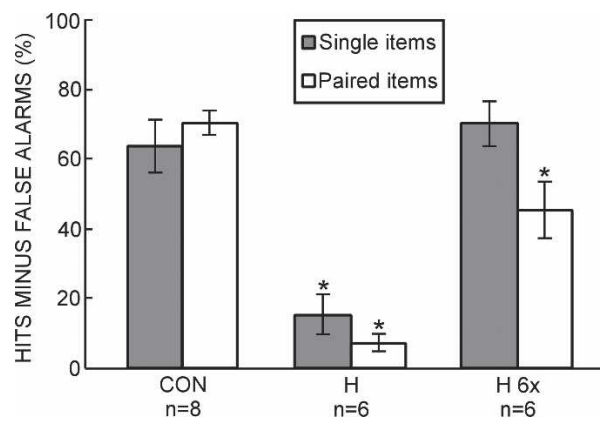

Figure 1. Combined memory test (Experiment 1). Hit rate minus falsealarm rate for controls ( $\mathrm{CON}, n=8)$ and patients with hippocampal lesions $(H, n=6)$ who studied 36 word pairs and then took a yes/no recognition memory test for studied words (single words from studied word pairs), new words, studied word pairs, and recombined word pairs. In a separate test $(\mathrm{H} 6 \times)$, the patients with hippocampal damage saw 36 word pairs six times each and then took the yes/no recognition test. An asterisk indicates a significant difference from CON $(P<0.05)$. Brackets indicate standard error of the mean.

both the single-item test $(37.0 \pm 6.8 \%$ vs. $65.6 \pm 5.0 \%, P<0.01)$ and on the paired-items test $(21.0 \pm 4.4 \%$ vs. $48.2 \pm 7.9 \%$, $P<0.05)$ (Fig. 2). The patients scored above chance level on both measures $(P<0.01)$. Repeated measures ANOVA revealed effects of group $(P<0.01)$ and test $(P<0.05)$ but no group $\times$ test interaction $(P>0.50)$. When patients $(\mathrm{H} 6 \times)$ saw each word (or word pair) six times, their scores matched the scores of controls on both the single-item test $(61.0 \pm 4.1 \%$ vs. $65.6 \pm 5.0 \%, P>0.50)$ and on the paired-items test $(38.9 \pm 8.0 \%$ vs. $48.2 \pm 7.9 \%$, $P>0.50)$ (Fig. 2). Repeated measures ANOVA revealed an effect of test $(P<0.05)$ but no effect of group $(P>0.40)$ and no group $\times$ test interaction $(P>0.50)$. Table 2 shows the hit rates and falsealarm rates for all three conditions $(\mathrm{CON}, \mathrm{H}$, and $\mathrm{H} 6 \times)$.

An analysis of discriminability $\left(\mathrm{d}^{\prime}\right)$ yielded similar results. Patients $(\mathrm{H})$ were impaired relative to controls $(\mathrm{CON})$ on both the single-item test $(1.05 \pm 0.21$ vs. $2.17 \pm 0.19, P<0.01)$ and on the paired-items test $(0.61 \pm 0.13$ vs. $1.45 \pm 0.25, P<0.05)$. The patients scored above chance level on both measures $(P<0.01)$. Repeated measures ANOVA revealed effects of group $(P<0.01)$ and test $(P<0.05)$ but no group $\times$ test interaction $(P>0.50)$. When patients $(\mathrm{H} 6 \times)$ saw each word (or word pair) on the study list six times, their scores matched the scores of controls on both the single-item test $(1.90 \pm 0.15$ vs. $2.17 \pm 0.19, P>0.40)$ and on the paired-items test $(1.14 \pm 0.22$ vs. $1.45 \pm 0.25, P>0.40)$. Repeated measures ANOVA revealed an effect of test $(P<0.01)$ but no effect of group $(P>0.30)$ and no group $\times$ test interaction $(P>0.50)$.

\section{Discussion}

We investigated the role of the hippocampal region in singleitem recognition memory and associative recognition memory. In Experiment 1 (Combined memory test), patients and controls studied pairs of words and then took a memory test in which studied words, new words, studied word pairs, and recombined word pairs were presented in a mixed order. The patients were impaired on both single-item memory and associative memory. In a second test, the performance of the patients was improved by presenting each study list six times. In this case, the performance of the patients on single-item memory was similar to the single-item performance of controls who saw the study list only once. However, the patients performed more poorly than controls on the measure of associative memory. These findings largely replicate earlier findings based on a similar test procedure (Giovanello et al. 2003).
In Experiment 2 (Separated memory test), patients and controls studied single words and then took a memory test involving studied words and new words. In a separate study/test sequence, patients and controls studied word pairs and took a memory test involving studied word pairs and recombined word pairs. With this procedure, associative recognition memory was more difficult than single-item recognition memory for both controls and for patients with hippocampal damage. In addition, relative to the controls, patients were impaired on both the single-item test and the paired-items test. In a second test, the performance of the patients was improved by presenting each study list six times. In this case, the performance of the patients on both the single-item test and the paired-items test was similar to the performance of controls who saw each study list only once. Thus, in the Separated memory test, patients with damage limited to the hippocampal region were similarly impaired at both single-item recognition memory and associative recognition memory.

Despite the fact that Experiments 1 and 2 both tested item memory and associative memory for words, the two experiments yielded different results. In Experiment 1, patients with hippocampal lesions appeared disproportionately impaired at associative memory relative to item memory, but in Experiment 2 the same patients were similarly impaired at associative memory and item memory. A suggestion about the origin of these different results comes from examining false-alarm rates. When separate single-item and paired-item tests were given (Experiment 2), controls and patients had a higher false-alarm rate in the paireditems test than in the single-items test (Table 2). This effect is well known when novel items are used as foils in single-item tests and recombined pairs are used as foils in paired-item tests (Table 2 of Stark and Squire 2003; Kroll et al. 1996; Reinitz et al. 1996). Indeed, both the patients tested by Giovanello et al. (2003) and the patients in our Experiment 1 exhibited the expected high false-alarm rate for recombined pairs (Table 3). In contrast, the controls tested by Giovanello et al. (2003) and the controls in our Experiment 1 had false-alarm rates for item pairs that were considerably lower than expected and similar to the false-alarm rates for single items (Table 3). As a result of these low false-alarm rates for recombined word pairs, performance of the controls on paired items was actually numerically better than their performance on single items (Table 3). Note that this aspect of control performance can account for the finding in Experiment 1 that the patients appeared disproportionately impaired at associative memory.

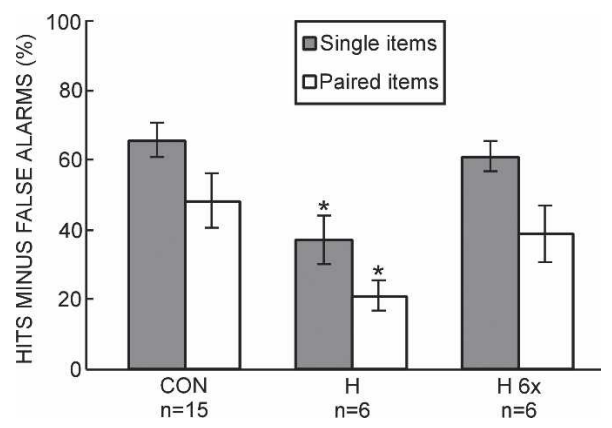

Figure 2. Separated memory test (Experiment 2). Hit rate minus falsealarm rate for controls (CON, $n=15$ ) and patients with hippocampal lesions $(H, n=6)$ who studied 36 single words or 18 word pairs. In a separate test $(\mathrm{H} 6 \times)$, the patients with hippocampal damage saw 36 single words six times each or 18 word pairs six times each. For the test of single words, participants took a yes/no recognition memory test for studied words and new words. For the test of word pairs, participants took a yes/no recognition memory test for studied word pairs and recombined word pairs. An asterisk indicates a significant difference from CON $(P<0.05)$. Brackets indicate standard error of the mean. 
Table 1. Hit rates and false-alarm rates for Experiment 1

\begin{tabular}{lccccc}
\hline & \multicolumn{2}{c}{ Hit rate } & & \multicolumn{2}{c}{ False-alarm rate } \\
\cline { 2 - 3 } \cline { 5 - 6 } & Single item & Paired items & & Single item & Paired items \\
\cline { 5 - 6 } & & & & & \\
$\mathrm{CON}$ & $74.0 \pm 4.6 \%$ & $81.8 \pm 3.8 \%$ & & $10.4 \pm 3.9 \%$ & $12.0 \pm 2.3 \%$ \\
$\mathrm{H}$ & $59.0 \pm 6.6 \%$ & $51.4 \pm 5.1 \%$ & & $43.8 \pm 8.7 \%$ & $44.4 \pm 4.0 \%$ \\
$\mathrm{H} 6 \times$ & $84.0 \pm 3.5 \%$ & $77.8 \pm 6.1 \%$ & & $13.9 \pm 5.5 \%$ & $32.6 \pm 6.6 \%$ \\
\hline
\end{tabular}

Percent hit rate and false-alarm rate (mean \pm standard error of the mean) for controls (CON, $n=8)$ and patients with hippocampal lesions $(H$, $n=6$ ) who studied 36 word pairs. In the $6 \times$ condition, the same patients with hippocampal damage $(\mathrm{H} 6 \times)$ saw 36 word pairs six times each.

In typical recognition memory tasks involving paired items, false-alarm rates are high for recombined pairs, presumably because recognition memory judgments are strongly influenced by familiarity (and recombined pairs are constructed from familiar items). In the Combined procedure used by Giovanello et al. (2003) and in our Experiment 1, controls may have learned not to make recognition judgments based on familiarity alone. Beginning with the practice trials presented prior to the study list, participants in the Combined procedure could recognize that they were being tested on two different tasks simultaneously (a single-item task and a paired-items task). Controls may have learned that these two different tasks could be approached with two different strategies (familiarity in the case of the single-item task and recollection in the case of the paired-items task). Such declarative knowledge (i.e., knowledge that associative recognition judgments based on familiarity are counterproductive) would be difficult for patients to acquire.

Alternatively, patients may have had difficulty remembering the complicated task instructions (i.e., respond "old" to single study words and to intact word pairs but respond "new" to single novel words and to recombined pairs of familiar words). In any case, in the present study when a different procedure was used (i.e., separate single-item and paired-item tests, Experiment 2), controls exhibited the expected high false-alarm rate, and the patients with damage limited to the hippocampal region were similarly impaired at associative memory and item memory. These considerations raise the possibility that the findings from Experiment 1 have limited generalizability. Indeed, the Combined procedure of Experiment 1 presents some difficulties. Although it may approximate real-world learning experiences (single items are often learned when they are presented as parts of associations), the Combined procedure is less useful as an analytic tool for comparing single-item memory and paired-item memory because a pure test of item memory is not available.

We also considered the implications of the fact that the encoding conditions for single items and paired words were not identical in the Separated procedure of Experiment 2. In Experiment 2 , single items were encoded by seeing each word and hearing it read aloud; paired items were encoded by seeing word pairs and hearing sentences that linked the words. If the patents did not encode the single items as deeply as the paired items, then the score for patients on the single-item test in Experiment 2 might have been spuriously low, thereby masking a disproportionate impairment on paired items. This possibility is unlikely. The performance of patients on the single-item test after six repetitions of the study list ( $\mathrm{H} 6 \times)$ was about the same in Experiment 2 as in Experiment 1 where deep encoding instructions were explicitly given. Thus, there was no indication in the data that the patients performed unusually poorly on the single-item test of Experiment 2.

The findings from Experiment 2 accord with the findings from earlier studies of memory-impaired patients that used twocomponent stimuli (e.g., pictures of faces and houses, pictures of two objects, two-syllable words, and two-syllable pseudo-words). In these studies, patients with damage thought to be limited to the hippocampal region were also similarly impaired at memory for associations and memory for single items (Stark et al. 2002; Stark and Squire 2003). Other studies of memory-impaired patients have also compared memory for associations and memory for single items (Kroll et al. 1996; Giovanello et al. 2003; Mayes et al. 2004; Turriziani et al. 2004). Patient YR performed similarly to controls on tests of item memory and tests of within-domain associative memory (e.g., word-word pairs or face-face pairs) but was impaired relative to controls on tests of cross-domain associative memory (e.g., word-face pairs) (Mayes et al. 2004). In other studies, patients performed similarly to controls on tests of item memory but were impaired on tests of within-domain associative memory (Kroll et al. 1996; Turriziani et al. 2004) and cross-domain associative memory (Turriziani et al. 2004). Lastly, as discussed earlier, Giovanello et al. (2003) found that memoryimpaired patients were impaired at both item memory and within-domain (word-word) associative memory but were more severely impaired at associative memory.

These studies do not converge on a single view. One possible source of the different findings is that the location and extent of brain damage, as well as the severity of memory impairment, vary in the patients that have been studied. For example, on the basis of quantitative, volumetric assessment of their lesions, our patients appear to have damage limited to the hippocampal region (Bayley et al. 2005; Gold and Squire 2005). In contrast, YR is the only patient in the other studies with quantitative evidence of damage limited to the hippocampal region (Mayes et al. 2004).

There has been considerable discussion of the idea that the hippocampus might be especially important for associative memory and less important for single-item memory, especially familiarity-based recognition (for review, see Brown and Aggleton 2001). Yet many questions remain, and there is reason to be cautious about assigning sharply different functions to these structures (for reviews, see Suzuki and Eichenbaum 2000; Squire et al. 2004; Wixted 2006). Indeed, it will be important to weigh recent evidence indicating that the hippocampus does support familiarity-based recognition judgments for single items (Rutishauser et al. 2006; Wais et al. 2006). In one study, recordings were made from hippocampal neurons in patients being evaluated for epilepsy surgery (Rutishauser et al. 2006). The patients first saw 12 visual images each presented in one of four locations on a computer screen. After $30 \mathrm{~min}$, they took a yes/no recognition memory test (12 studied images and 12 novel images). For images identified as familiar, patients were also asked to indicate the location in which the image was originally presented. One class of neurons responded to familiar images during the test phase, and these familiarity responses were present even on trials where spatial recollection failed. These findings demonstrate directly that the human hippocampus signals single-item familiar-

Table 2. Hit rates and false-alarm rates for Experiment 2

\begin{tabular}{|c|c|c|c|c|}
\hline & \multicolumn{2}{|c|}{ Hit rate } & \multicolumn{2}{|c|}{ False-alarm rate } \\
\hline & Single item & Paired items & Single item & Paired items \\
\hline $\mathrm{CON}$ & $75.6 \pm 3.7 \%$ & $74.8 \pm 4.7 \%$ & $10.0 \pm 3.3 \%$ & $26.7 \pm 5.1 \%$ \\
\hline $\mathrm{H}$ & $69.4 \pm 3.7 \%$ & $60.5 \pm 8.5 \%$ & $32.4 \pm 7.9 \%$ & $39.5 \pm 6.8 \%$ \\
\hline $\mathrm{H} 6 \times$ & $85.9 \pm 4.6 \%$ & $70.3 \pm 10.2 \%$ & $25.0 \pm 6.9 \%$ & $31.5 \pm 6.7 \%$ \\
\hline
\end{tabular}

Percent hit rate and false-alarm rate (mean \pm standard error of the mean) for controls (CON, $n=15$ ) and patients with hippocampal lesions $(H$, $n=6$ ) who studied either 36 single words or 18 word pairs. In the $6 \times$ condition, the same patients with hippocampal damage $(\mathrm{H} 6 \times)$ saw either 36 single words six times each or 18 word pairs six times each.

\section{Learning \& Memory \\ www.learnmem.org}


Table 3. Hit rates and false-alarm rates for Experiment 1

\begin{tabular}{lccccc}
\hline & \multicolumn{2}{c}{ Hit rate } & & \multicolumn{2}{c}{ False-alarm rate } \\
\cline { 2 - 3 } \cline { 5 - 6 } \cline { 5 - 6 } & Single item & Paired items & & Single item & Paired items \\
\hline CON & $74 \%$ & $82 \%$ & & $10 \%$ & $12 \%$ \\
H 6 & $84 \%$ & $78 \%$ & & $14 \%$ & $33 \%$ \\
G.CON & $76 \%$ & $97 \%$ & & $6 \%$ & $8 \%$ \\
G.MTL 6x & $77 \%$ & $73 \%$ & & $15 \%$ & $36 \%$ \\
\hline
\end{tabular}

Mean percent hit rate and false-alarm rate for controls (CON, $n=8$ from the present study and G.CON, $n=11$ as reported in Table 2 of Giovanello et al. 2003) and memory-impaired patients ( $\mathrm{H} 6 \times, n=6$ from the present study and G.MTL $6 \times, n=10$ as reported in Table 2 of Giovanello et al. 2003). Participants studied 36 word pairs and took a yes/no recognition memory test for studied words, new words, studied word pairs, and recombined word pairs. Patients in both studies saw 36 word pairs six times each.

ity memory and that associative information is not required for these signals to be observed.

In summary, we used two tasks to investigate memory for single items and memory for associations. In both tasks, patients with damage limited to the hippocampal region were impaired at memory for single items and memory for associations, suggesting that the hippocampus is important for both of these memory functions. In Experiment 1 (Combined memory test), the patients appeared to be more impaired at associative memory than item memory. In Experiment 2 (Separated memory test), the patients were similarly impaired at associative memory and item memory. We noted that in Experiment 1 controls provided unexpectedly low false-alarm rates for recombined foils and, thereby, obtained high scores for the paired-item condition. This elevated control score can account for the appearance of an especially severe impairment in the patient group in Experiment 1. Accordingly, one should allow for the possibility that the findings from Experiment 1 are of limited generalizability.

\section{Materials and Methods}

\section{Experiment 1: Combined memory test}

\section{Patients}

The memory-impaired patients were five men and one woman with damage thought to be limited to the hippocampal region (dentate gyrus, CA fields, and subiculum) (Table 4). G.W. and R.S. became amnesic following a drug overdose and associated respiratory failure in 2001 and 1998, respectively. K.E. became amnesic in 2004 following an episode of ischemia associated with kidney failure and toxic shock syndrome. J.R.W. and A.B. became amnesic following an episode of cardiac arrest in 1990 and 1976, respectively. L.J. (the female) became amnesic in 1988 during a 6-mo period with no known precipitating event.

For five of the six patients (excluding A.B., see below), esti- mates of medial temporal lobe damage were based on quantitative analysis of magnetic resonance images (MRI), compared with data for 19 controls (K.E., R.S., G.W., and J.R.W.) or 11 controls (L.J.) (Gold and Squire 2005). The volumes of the full anteriorposterior length of the hippocampus and the parahippocampal gyrus were measured using criteria based on histological analysis of healthy brains (Amaral and Insausti 1990; Insausti et al. $1998 \mathrm{a}, \mathrm{b})$. For each patient, the volumes of the hippocampus and parahippocampal gyrus were divided by the intracranial volume to correct for brain size. K.E., L.J., R.S., G.W., and J.R.W. have an average bilateral reduction in hippocampal volume of $49 \%, 46 \%$, $33 \%, 48 \%$, and $44 \%$, respectively (all values $>3.0$ SDs below the control mean). In comparison, the volume of the parahippocampal gyrus (temporopolar cortex, perirhinal, entorhinal, and parahippocampal cortices) is reduced by $17 \%,-8 \%, 1 \%, 12 \%$, and $6 \%$, respectively (all values within 2 SDs of the control mean). On the basis of two patients (L.M. and W.H.) with similar bilateral volume loss in the hippocampus for whom detailed postmortem neurohistological information was obtained (Rempel-Clower et al. 1996), this degree of volume loss likely reflects nearly complete loss of hippocampal neurons (also see Gold and Squire 2005).

Additional measurements, based on four controls for each patient, were carried out for the insular cortex, fusiform gyrus, frontal lobes, lateral temporal lobes, parietal lobes, and occipital lobes. The only volume reduction in these regions $>1.3 \mathrm{SDs}$ of the control mean was the parietal lobe for R.S. (Bayley et al. 2005).

The sixth patient (A.B.) was unable to participate in MRI studies because he had an implanted pacemaker. His etiology (anoxia) and neurologic examination suggest hippocampal damage and well-circumscribed amnesia. In addition, high-resolution computed tomography (CT) images obtained in 2001 were consistent with restricted damage to the hippocampal region (Schmolck et al. 2002).

For the six patients, immediate and delayed (12-min) recall of a short prose passage (Gilbert et al. 1968) averaged 4.7 and 0.3 segments, respectively.

Controls

The participants in the control group were eight volunteers (two female) recruited from the San Diego community (age $=60.9 \pm 2.9 \mathrm{yr}$, education $=13.1 \pm 0.9 \mathrm{yr})$. Their immediate and delayed prose recall averaged 7.0 and 6.6 segments, respectively.

\section{Materials}

Materials were drawn from a pool of nouns (40-300 occurrences per million; Kucera and Francis 1967). For the study phase, 72 words were used to create 36 word pairs. For the test phase, 12 word pairs were chosen randomly to serve as associative targets and 12 words were chosen randomly to serve as single-item targets. Twenty-four of the remaining words were recombined into new word pairs to serve as associative foils, and 12 new words served as single-item foils. Single words and word pairs (both targets and foils) were presented in a mixed order such that no more than three targets or three foils appeared consecutively.

Table 4. Characteristics of amnesic patients

\begin{tabular}{|c|c|c|c|c|c|c|c|c|}
\hline \multirow[b]{2}{*}{ Patient } & \multirow{2}{*}{$\begin{array}{c}\text { Age } \\
\text { (years) }\end{array}$} & \multirow{2}{*}{$\begin{array}{l}\text { Education } \\
\text { (years) }\end{array}$} & \multirow[b]{2}{*}{ WAIS-III IQ } & \multicolumn{5}{|c|}{ WMS-R } \\
\hline & & & & Attention & Verbal & Visual & General & Delay \\
\hline A.B. & 69 & 20 & 107 & 87 & 62 & 75 & 54 & $<50$ \\
\hline K.E. & 63 & 13.5 & 108 & 114 & 64 & 84 & 72 & 55 \\
\hline L.J. & 67 & 12 & 101 & 105 & 83 & 60 & 69 & $<50$ \\
\hline R.S. & 45 & 12 & 99 & 99 & 85 & 81 & 82 & $<50$ \\
\hline G.W. & 45 & 12 & 108 & 105 & 67 & 86 & 70 & $<50$ \\
\hline J.R.W & 38 & 12 & 90 & 87 & 65 & 95 & 70 & $<50$ \\
\hline
\end{tabular}

The Wechsler Adult Intelligence Scale-III (WAIS-III) and the Wechsler Memory Scale-Revised (WMS-R) yield mean scores of 100 in the normal population with a standard deviation of 15 . The WMS-R does not provide numerical scores for individuals who score $<50$. IQ scores for J.R.W. and R.S. are from the Wechsler Adult Intelligence scale-Revised. 


\section{Procedure}

For the study phase, participants saw 36 word pairs one at a time on a computer screen (self-paced) and were asked to remember each word for a later memory test. Participants were also instructed to remember which words were presented together. A sentence that related the two words was read aloud to the participants. After one minute, participants took a yes/no memory test for 12 old pairs, 12 recombined pairs, 12 old words, and 12 novel words.

Controls (CON) and the patients with hippocampal lesions (H) both took two different versions of this test, and the results from the two tests were averaged. The patients also took a different test in which they received six repetitions of the study list $(\mathrm{H}$ $6 \times)$. For the $\mathrm{H} 6 \times$ group, study pairs were presented in a different order for each repetition. A second version of this test was also given.

\section{Experiment 2: Separated memory test}

\section{Patients}

The patients were the same as in Experiment 1.

\section{Controls}

Seven of the eight controls from Experiment 1 participated in Experiment 2, as well as eight additional controls recruited from the San Diego community. In total, there were 15 controls (four female, age $=58.3 \pm 3.1 \mathrm{yr}$, education $=14.3 \pm 0.70 \mathrm{yr}$ ). Their immediate and delayed prose recall averaged 7.7 and 6.7 segments, respectively.

\section{Materials}

Materials were drawn from a pool of nouns (40-300 occurrences per million; Kucera and Francis 1967). For the single-item test, 36 words served as study words. For the test phase, 24 of the 36 study words were selected randomly to serve as targets. Twentyfour additional words served as foils. Target words and foil words were presented in a mixed order such that no more than three target words or three foil words appeared consecutively.

For the paired-items test, 36 words were used to create 18 study pairs. For the test phase, nine of the 18 study pairs served as target pairs and nine pairs were recombined to serve as foil pairs. Target pairs and foil pairs were presented in a mixed order such that no more than three target pairs or three foil pairs appeared consecutively. Study words were equally likely to appear on a single-item test or on a paired-items test.

\section{Procedure}

For the single-item test, participants saw 36 words one at a time on a computer screen (self-paced) and were asked to remember each word for a later memory test. Each word was also read aloud to the participants as it appeared on the screen. Words were presented either once (CON and $\mathrm{H}$ groups) or six times $(\mathrm{H} 6 \times$ group). After one minute, participants took a yes/no memory test for 24 old words and 24 foil words.

For the paired-items test, participants saw 18 word pairs one at a time on a computer screen (self-paced) and were asked to remember each pair for a later memory test. A sentence that related the two words was read aloud to the participants. After one minute, participants took a yes/no memory test for nine old pairs and nine recombined pairs.

Controls $(\mathrm{CON})$ took one single-item test and one paireditems test. The patients with hippocampal lesions $(\mathrm{H})$ took the same tests as controls, plus two additional single-item tests and two additional paired-items tests constructed from new words. The patients also took a different single-item test and paireditems test and received six repetitions of each study list $(\mathrm{H} 6 \times)$. For the $\mathrm{H} 6 \times$ group, study words and study pairs were presented in a different order for each repetition.

For all but two participants, test sessions were scheduled on different days and consisted of one single-item test and one paired-items test (with test order counterbalanced across participants). Patient R.S. took two of the single-item tests and two of the paired-items tests during a several-hour period on the same day, and patient J.R.W. took three of the single-item tests and three of the paired-item tests during a several-hour period on the same day.

\section{Acknowledgments}

This work was supported by the Medical Research of the Department of Veterans Affairs, National Institute of Mental Health (NIMH) Grant MH24600, the Metropolitan Life Foundation, and NIMH Training Grant 5-T32-MH20002 (J.J.G.). We thank Jen Frascino, Leah Swalley, and Mark Starr for assistance.

\section{References}

Amaral, D.G. and Insausti, R. 1990. Hippocampal formation. In The human nervous system (ed. G. Paxinos), pp. 711-755. Academic Press, San Diego.

Bayley, P.J., Gold, J.J., Hopkins, R.O., and Squire, L.R. 2005. The neuroanatomy of remote memory. Neuron 46: 799-810.

Brown, M.W. and Aggleton, J.P. 2001. Recognition memory: What are the roles of the perirhinal cortex and hippocampus? Nat. Rev. Neurosci. 2: 51-61.

Burwell, R.D., Suzuki, W.A., Insausti, R., and Amaral, D.G. 1996. Some observations on the perirhinal and parahippocampal cortices in the rat, monkey, and human brains. In Perception, memory and emotion: Frontiers in neuroscience (eds. T. Ono et al.), pp. 95-110. Cambridge University Press, UK.

Eichenbaum, H., Otto, T., and Cohen, N.J. 1994. Two component functions of the hippocampal memory system. Behav. Brain Sci. 17: 449-517.

Gilbert, J.G., Levee, R.F., and Catalano, F.L. 1968. A preliminary report on a new memory scale. Percept. Mot. Skills 26: 277-278.

Giovanello, K.S., Verfaellie, M., and Keane, M.M. 2003. Disproportionate deficit in associative recognition relative to item recognition in global amnesia. Cogn. Affect. Behav. Neurosci. 3: 186-194.

Gold, J.J. and Squire, L.R. 2005. Quantifying medial temporal lobe damage in memory-impaired patients. Hippocampus 15: 79-85.

Henke, K., Buck, A., Weber, B., and Wieser, H.G. 1997. Human hippocampus establishes associations in memory. Hippocampus 7: 249-256.

Henke, K., Weber, B., Kneifel, S., Wieser, H.G., and Buck, A. 1999. Human hippocampus associates information in memory. Proc. Natl. Acad. Sci. 96: 5884-5889.

Insausti, R., Insausti, A.M., Sobreviela, M.T., Salinas, A., and Martinez-Penuela, J.M. 1998a. Human medial temporal lobe in aging: Anatomical basis of memory preservation. Microsc. Res. Tech. 43: 8-15.

Insausti, R., Juottonen, K., Soininen, H., Insausti, A.M., Partanen, K., Vainio, P., Laakso, M.P., and Pitkänen, A. 1998b. MR volumetric analysis of the human entorhinal, perirhinal, and temporopolar cortices. AJNR Am. J. Neuroradiol. 19: 659-671.

Kroll, N.E.A., Knight, R.T., Metcalfe, J., Wolf, E.S., and Tulving, E. 1996. Cohesion failure as a source of memory illusions. J. Mem. Lang. 35: $176-196$.

Kucera, H. and Francis, W.N. 1967. Computational analysis of present-day American English. Brown University Press, Providence, RI.

Lavenex, P. and Amaral, D.G. 2000. Hippocampal-neocortical interaction: A hierarchy of associativity. Hippocampus 10: 420-430.

Mayes, A.R., Holdstock, J.S., Isaac, C.L., Montaldi, D., Grigor, J., Gummer, A., Cariga, P., Downes, J.J., Tsivilis, D., Gaffan, D., et al. 2004. Associative recognition in a patient with selective hippocampal lesions and relatively normal item recognition. Hippocampus 14: 763-784.

Reinitz, M.T., Verfaellie, M., and Milbert, W.P. 1996. Memory conjunction errors in normal and amnesic subjects. J. Mem. Lang. 35: $286-299$.

Rempel-Clower, N.L., Zola, S.M., Squire, L.R., and Amaral, D.G. 1996. Three cases of enduring memory impairment after bilateral damage limited to the hippocampal formation. J. Neurosci. 16: 5233-5255.

Rutishauser, U., Mamelak, A.N., and Schuman, E.M. 2006. Single-trial learning of novel stimuli by individual neurons of the human hippocampus-amygdala complex. Neuron 49: 805-813.

Schmolck, H., Kensinger, E.A., Corkin, S., and Squire, L.R. 2002. Semantic knowledge in patient H.M. and other patients with bilateral medial and lateral temporal lobe lesions. Hippocampus 12: $520-533$.

Squire, L.R., Stark, C.E., and Clark, R.E. 2004. The medial temporal lobe. Annu. Rev. Neurosci. 27: 279-306. 
Stark, C.E. and Squire, L.R. 2003. Hippocampal damage equally impairs memory for single items and memory for conjunctions. Hippocampus 13: $281-292$.

Stark, C.E., Bayley, P.J., and Squire, L.R. 2002. Recognition memory for single items and for associations is similarly impaired following damage to the hippocampal region. Learn. Mem. 9: 238-242.

Suzuki, W.A. and Eichenbaum, H. 2000. The neurophysiology of memory. Ann. N.Y. Acad. Sci. 911: 175-191.

Turriziani, P., Fadda, L., Caltagirone, C., and Carlesimo, G.A. 2004.
Recognition memory for single items and for associations in amnesic patients. Neuropsychologia 42: 426-433.

Wais, P.E., Wixted, J.T., Hopkins, R.O., and Squire, L.R. 2006. The hippocampus supports both the recollection and the familiarity components of recognition memory. Neuron 49: 459-466.

Wixted, J.T. 2006. Dual-process theory and signal-detection theory of recognition memory. Psychol. Rev. (in press).

Received March 20, 2006; accepted in revised form July 13, 2006. 


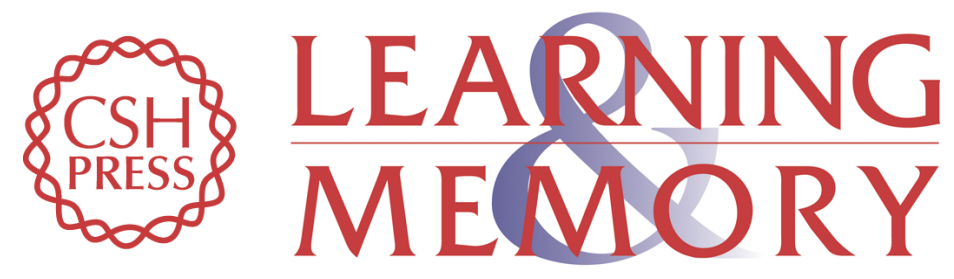

\section{Single-item memory, associative memory, and the human hippocampus}

Jeffrey J. Gold, Ramona O. Hopkins and Larry R. Squire

Learn. Mem. 2006, 13:

Access the most recent version at doi:10.1101//m.258406

References This article cites 23 articles, 3 of which can be accessed free at:

http://learnmem.cshlp.org/content/13/5/644.full.html\#ref-list-1

License

Email Alerting Receive free email alerts when new articles cite this article - sign up in the box at the Service top right corner of the article or click here. 